\title{
Review
}

\section{MRS conference review: Tracking a decade of changing Britain} From Open Data to the
'post-2011' generation
ONS is working on benefits realization

\section{Census output geography matters}

This one-day conference, held on 6 November 2013, had two main themes: to illustrate early uses of the 2011 Census and to discuss recent wider developments in Open Data. One of the foremost uses of Census data is, of course, as an input for geo-demographic systems that encapsulate the characteristics of a neighbourhood in a simple classification or code. The day was structured in order to reflect this focus. In the morning session, chaired by Peter Furness of Peter Furness Limited, speakers examined findings and benefits from the Census, together with the wide-ranging applications of Open Data. The afternoon, chaired by Peter Sleight of Target Market Consultancy, was devoted to the 'post-2011' generation of geo-demographic discriminators.

\section{Morning session: 2011 census and Open Data}

The first speaker, David Martin from Southampton University, set the scene on the 2011 Census and laid down a number of pointers for the remainder of the day. Martin commented on why 2011 is being seen as the best Census of recent times and illustrated the importance of reusing the 2001 output geography for 2011 . He presented examples showing how the populations of areas have changed over the decade - such as the East End becoming younger and the outer South East getting older - which helpfully informed this reviewer on where to search for his next home. David went on to explain the current development of a special geography for analysing workplace results from the Census, before reminding delegates to consider carefully the future options in the 'Beyond 2011' consultation and have their say before it's too late.

In the last couple of years, ONS has been making progress in learning how Census results are applied, collecting together example use cases and attempting to quantify the financial benefits of Census data. Oliver Doerle from ONS presented next on realizing benefits from the Census. Doerle explained that the ONS approach was intended, in part, to ensure that the Census outputs are fully used, and partly to assemble examples of economic benefits that will feed into the Beyond 2011 business case. This work is based on a combination of user surveys and direct engagement with various bodies. It has resulted in a new section of the ONS website on 2011 Census benefits (http://www.ons.gov.uk/ons/guide-method/census/ 2011/2011-census-benefits/index.html). 


\section{Social grade remains important}

\section{Open data successes and failures}

\section{Mapping recession effects}

\section{'Census data no longer essential'}

Doerle also updated delegates on ONS plans for further Census outputs, including origin-destination data that will provide information on flow patterns, such as migration and commuting - telling us, for example, how many people travel to work in Teddington and where they come from.

The next talk gave a specific example of Census use. Helen Lambert of GfK NOP presented a fascinating case study on how social grade has been modelled on the 2011 Census. Lambert first demonstrated the importance of the $\mathrm{ABC} 1$ classification that is used widely in advertising and marketing. She then explained the model development, which was very much akin to targeting models employed in direct marketing, except that the target variable was social grade, the modelling data was the National Readership Survey and the prospect database was the Census. Finally, Lambert presented numerous example maps to illustrate the Census results for various parts of London - again, this reviewer took careful note for house-hunting purposes.

The final speaker of the morning - Heather Savory, chair of the Open Data User Group (ODUG) - made a very strong case for Open Data, citing multi-billion pound benefits to the UK economy and to the geo-services industry. Savory explained that ODUG advises the Public Sector Transparency Board on public sector data that should be prioritized for release as open data and described the way that ODUG operates. Since its formation in mid-2012, ODUG has had some notable successes, including the release of Land Registry price paid data, but has also met some challenges - notably on obtaining an open national address data set, although ODUG has ensured that Government takes a look at the options open to it.

\section{Afternoon session: Geo-demographic developments}

Peter Sleight, who chaired the afternoon session, also happens to have been a leading player in the geo-demographics industry for most of its 35-year history. Sleight introduced the afternoon by reviewing the history of 'geodems' - the background of past classifications is an essential prerequisite for understanding future ones.

The first speaker of the afternoon, Simon Whalley from Beacon Dodsworth, discussed the new $\mathrm{P}^{2}$ People \& Places discriminator, which will help to explore how the recession has affected people. This classification has involved clustering the United Kingdom's primary urban areas economically based on the factors that affect the performance of a city, such as the rate of business churn, the level of knowledge-based intensive services and the incidence of most highly skilled workers. Whalley illustrated the results with maps on different parts of the United Kingdom, including Cambridge, which is part of the 'Qualified Growth' cluster, due to having high levels of qualified people, many high-tech companies and potential for growth. The final stage will be to build $\mathrm{P}^{2}$ People \& Places inside the economic clusters.

John Rae of CACI described a very different approach to geodemographics created and applied when building the new ACORN system. In the new world invented by CACI, the segmentation structure is devised 
CAMEO still using Census data

\section{Census provides context for SoLoMo}

\section{Chelsea fans are 'Cosmopolitans'}

first, and then areas are allocated to segments using different methods and different data, according to the circumstances. Rae explained that ACORN was built and tested before the release of Census data. Subsequently, CACI tested the effect of adding Census variables and found that they made little difference - therefore, the Census is 'nice to have, but not essential'.

Paul Kennedy from Callcredit Information Group described the approach that his company is taking to rebuilding the CAMEO segmentation. Unlike CACI, Callcredit has decided to use Census data as the backbone for its product. Kennedy explained the importance of Census for understanding migration and ethnicity, as well as for tracking population change. He highlighted the diverse range of behavioural, lifestyle and survey data sets that will be used in building CAMEO — both for creating colourful descriptions and for 'dynamic updates'.

The last of the commercial presenters, Andy Bell from Pitney Bowes Software, focused on explaining how 2011 Census data supports social, local and mobile (SoLoMo) solutions. According to Bell, consumers now expect brands to deliver personalized experiences, using more precise locational and behavioural information. Census and geo-demographic data will enhance these services by providing the context about people, according to where they live. Pitney Bowes plans to merge these sources together with other disparate data - such as consumer and business locations, types of areas and points of interest - for location-based profiling and targeting.

The final presentation of the afternoon came from the academic sector - Chris Gale from UCL presented on the 2011 Output Area Classification (OAC), which has been developed in partnership with ONS. OAC 2011 follows the broad approach taken for OAC 2001 and is the only geo-demographic discriminator that solely employs Census data. Gale explained that a larger number of variables were available for 2011, resulting in a classification that contains a greater number of categories at each level. He illustrated OAC 2011very effectively, using a large number of colourful maps and charts. However, the simplest comparison was also the most memorable: most of the people who live near Liverpool FC are 'Hard-Pressed Households', while those living near Chelsea FC are mainly 'Cosmopolitans'.

Sleight wrapped up the afternoon by presenting progress reports from other developers who are currently building 2011 geodem classifications, including Personicx from Acxiom, Mosaic from Experian, Censation from AFD and Sonar from TRAC. This completed a spellbinding afternoon no two presentations were alike or overlapped and all the developers seem to have taken different approaches for their classifications. Therefore, geodem users can look forward to being spoilt for choice in 2014.

(A detailed Chairmen's Report, as well as all presentations from this event, may be accessed at: https://www.mrs.org.uk/intelligence/cgg/ events/trackingadecade) 